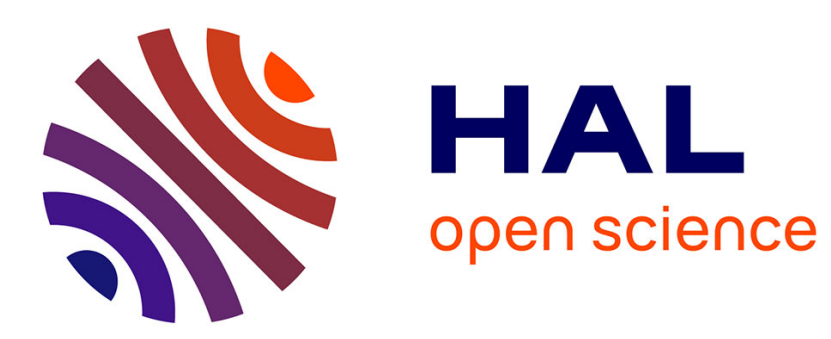

\title{
A two yielding surface elasto-plastic model with consideration of grain breakage
}

Wei Hu, Christophe Dano, Pierre-Yves Hicher

\section{To cite this version:}

Wei Hu, Christophe Dano, Pierre-Yves Hicher. A two yielding surface elasto-plastic model with consideration of grain breakage. GeoShanghai International Conference, 2010, Shanghai, China. 10.1061/41101(374)17 . hal-01007817

\section{HAL Id: hal-01007817 https://hal.science/hal-01007817}

Submitted on 21 Sep 2018

HAL is a multi-disciplinary open access archive for the deposit and dissemination of scientific research documents, whether they are published or not. The documents may come from teaching and research institutions in France or abroad, or from public or private research centers.
L'archive ouverte pluridisciplinaire HAL, est destinée au dépôt et à la diffusion de documents scientifiques de niveau recherche, publiés ou non, émanant des établissements d'enseignement et de recherche français ou étrangers, des laboratoires publics ou privés. 


\title{
A Two Yielding Surface Elasto-Plastic Model with Consideration of Grain Breakage
}

\author{
Hu Wei, Dano Christophe, Pierre-Yves Hicher
}

Research Institute in Civil and Mechanical Engineering, UMR CNRS 6183, Ecole Centrale de Nantes, 44321 Nantes, France;wei.hu@ec-nantes.fr

\begin{abstract}
An elasto-plastic model with two yield surfaces has been developed for the simulation of granular materials with consideration of grain ruptures. Grain breakage is induced by deviatoric as well as isotropic stresses. One yield function is based on a Mohr-Coulomb criterion with a hyperbolic hardening function of the plastic deviatoric strain. A second yield function is introduced to describe the plastic behaviour under compression, in which a hardening function of the plastic volumetric strain is introduced. The main assumption of this model is that, upon loading, the position of the critical state changes as a consequence of grain breakage. The effect of the grain size distribution is introduced in the relationship between the void ratio at critical state and the mean effective stress. Triaxial and oedometer tests have been performed on crushable granular materials. Comparison of experimental results and numerical simulations shows that the new model can reproduce with good accuracy the behaviour of granular materials subjected to grain ruptures during mechanical loading.
\end{abstract}

\section{INTRODUCTION}

Grain crushing is very common in granular materials. Some experimental results (Marsal 1967, Vesic \& Clough1968, Hardin 1985, Kim 1995)have shown that grain crushing in a granular material occurs along deviatoric stress path as well as along isotropic stress path. Although it is agreed that deviatoric stresses induce more ruptures than isotropic stresses, the ruptures which are created by compression cannot be neglected. In order to consider the ruptures induced by isotropic and deviatoric stresses, an elasto-plastic model with two yield surfaces has been developed. Ruptures of particles are taken into account in the model by the evolution of the critical state. Indeed, ruptures of particles will produce a continuous evolution of the gradation and this change in the grain size distribution will provoke an evolution of the critical state of the material (Biarez and Hicher 1997). This evolution will be linked to the stress and strain amplitudes along a given loading path.

\section{STRESS - STRAIN RELATIONSHIP}

The constitutive model is an elasto-plastic model with two yield surfaces. The first 
yield surface is based on a Mohr-Coulomb criterion and a hyperbolic function is added into the model to be the hardening function. The second yield surface is a yield function for compression and a hardening function which includes the volumetric plastic strain is added. Critical state is also added into the model.

\section{Non-linear elasticity}

A non-linear hypo-elasticity has been selected. Young's modulus $E$ and shear modulus $G$ are power functions of the mean effective stress $p^{\prime}$

$$
\begin{gathered}
G=G_{0}\left(\frac{p^{\prime}}{p_{0}{ }^{\prime}}\right)^{n} \\
E=E_{0}\left(\frac{p^{\prime}}{p_{0}{ }^{\prime}}\right)^{n}
\end{gathered}
$$

$G_{0}$ and $E_{0}$ being the values of $E$ and $G$ for the reference mean effective stress $p_{0}{ }^{\prime}$. The parameters $G_{0}, p_{0}{ }^{\prime}$ and $n$ can be measured during a loading test by using, for example, bender elements technique.

\section{The first yield function}

The first yield function, noted as $F_{1}$, takes the following form

$$
F_{1}\left(p^{\prime}, q, \theta, \kappa_{1}\right)=\frac{q}{M_{p}} \times m(\theta)-p^{\prime} \times \kappa_{1}\left(\varepsilon_{d}^{p}\right)=0
$$

where $q$ is the deviator stress,

$$
q=\sqrt{3 \times J_{2}}
$$

$J_{2}$ is the second stress invariant:

$$
J_{2}=\frac{1}{2} s_{i j}: s_{i j}
$$

$S_{i j}$ is a component of the deviatoric stress tensor:

$$
s_{i j}=\sigma_{i j}-\frac{1}{3} \operatorname{Tr}\left(\sigma_{i j}\right) \times \delta_{i j}
$$

$p^{\prime}$ is the effective mean stress: 


$$
p^{\prime}=I_{1} / 3
$$

and

$$
\theta=-\frac{1}{3} \operatorname{Arcsin}\left(\frac{3 \sqrt{3}}{2} \frac{J_{3}}{J_{2}^{3 / 2}}\right)
$$

where

$$
J_{3}=\operatorname{det}\left(s_{i j}\right)
$$

We have chosen a specific function of $m(\theta)$ in order to obtain the Mohr-Coulomb yield surface (Bardet,1980):

$$
m(\theta)=\frac{6}{\sqrt{3}(3-\sin \varphi)}\left[\cos \theta-\frac{\sin \varphi}{\sqrt{3}} \sin \theta\right]
$$

\section{Hardening function for the Mohr-Coulomb yield surface}

The equation of the hardening function for the first yield function takes the following form:

$$
\kappa_{1}\left(\varepsilon_{d}^{p}\right)=r_{e l}+\frac{\varepsilon_{d}^{p}\left(1-r_{e l}\right)}{a+\varepsilon_{d}^{p}}
$$

Here $r_{e l}$ and $a$ are two material parameters. $r_{e l}$ defines the size of the initial elastic domain and $a$ controls the rate of the deviatoric plastic strain. $\kappa_{1}\left(\varepsilon_{d}^{p}\right)$ is an increasing function of $\varepsilon_{d}^{p}$. When $\varepsilon_{d}^{p}=0$ (no plastic deformation), the function $\kappa_{1}\left(\varepsilon_{d}^{p}\right)$ is equals to $r_{e l}$. When the perfect plastic state is reached $\left(\varepsilon_{d}^{p} \rightarrow \infty\right)$, the value of the hardening function is equal to 1 .

\section{Plastic potential for the first yield surface}

The plastic potential function is:

$$
G_{1}\left(p^{\prime}, q\right)=\frac{q}{M_{c}(\theta) \times p^{\prime}}+\operatorname{Ln}\left(p^{\prime}\right)
$$

$G_{1}$ is different from $F_{1}$, therefore the model is non-associated. $M_{c}(\theta)$ has the following expression :

$$
M_{c}(\theta)=M_{c} \times \frac{\sqrt{3}\left(3-\sin \varphi_{c}\right)}{6\left(\cos \theta-\frac{\sin \varphi_{c}}{\sqrt{3}} \sin \theta\right)}
$$


$\varphi_{c}$ is the characteristic angle which corresponds to the transition from the contracting domain to the dilating one:

$$
\varphi_{c}=\operatorname{Arcsin}\left(\frac{3 M_{c}}{6+M_{c}}\right)
$$

\section{The second yield function}

In order to describe the behavior of granular materials along isotropic loading and to consider ruptures induced by compression, a second yield surface is added into the model. The second yield function is assumed to be as follows:

$$
F_{2}\left(\sigma, \kappa_{2}\right)=p^{\prime}-\kappa_{2}\left(\varepsilon^{p}\right) \quad \text { for } \sigma>P_{p}
$$

$\kappa_{2}$ is another hardening function for the second yielding function which can be written as:

$$
\kappa_{2}=P_{p} 10^{\varepsilon^{p} / c^{p}}
$$

where $c^{p}$ is the compression coefficient in the $\varepsilon^{p}-\log \sigma^{\prime}$ coordinate system. When compression $\sigma$ is less than $P_{p}$, the plastic strain produced by the second yield function is null. $P_{p}$ corresponds to the pre-consolidated stress. We assume that the isotropic compression and the critical state are parallel lines in the $e-\log p^{\prime}$ plane by taking $c^{p}=\lambda$, where $\lambda$ is the slope of critical state line.

The potential function we have chosen for the second yielding surface is very simple and is to only give a possible direction of plastic deformation, which is parallel to the axis of isotropic compression in the $p^{\prime}-q$ plan.

$$
G_{2}\left(p^{\prime}, q\right)=p^{\prime}+k
$$

where $k$ is a constant.

\section{Critical state}

One of the most important concepts in soil mechanics is the critical state theory. At critical state, the material will remain at a constant volume while subjected to a continuous distortion. The void ratio corresponding to this state is $e_{c}$. The critical void ratio is a function of the mean effective stress $p^{\prime}$. The relationship can be expressed as:

$$
e_{c}=e_{r e f}-\lambda \log \left(\frac{p^{\prime}}{p_{r e f}}\right)
$$


The parameters $\left(e_{r e f}, p_{r e f}\right)$ correspond to a reference point on the critical state line. The internal friction angle $\phi_{u}$ is a constant for the material. But the peak friction angle $\phi_{p}$ is dependent on the stress state and the void ratio:

$$
\tan \phi_{p}=\left(\frac{e_{c}}{e}\right)^{m} \tan \phi_{u}
$$

where $m$ is a material constant (Biarez and Hicher 1994). In most conditions, the friction angle $\phi_{u}$ is assumed to be equal to the characteristic angle $\varphi_{c}$.

\section{Taking into account grain rupture in the constitutive model}

As shown in Figure 1, the critical state line in the $e-\log p^{\prime}$ plane depends on the grain size distribution. If grain breakage occurs during loading, the grain size distribution evolves and the value of $d_{60} / d_{10}$ increases. As a consequence, the critical state line is shifted towards the lower values of $e$, but the slope of the line remains almost constant. A simple way to describe the change of the critical state is to change the reference critical point $\left(e_{r e f}, p_{\text {ref }}\right)$.If one can assume that the slope remains constant, $e_{r e f}$ is the only variable necessary to control the evolution of the critical state line. For a given material the amount of grain breakage increases when increasing stresses and strains (Kim 1995). A simple way to consider the evolution of $e_{r e f}$ is therefore to make it a function of the two state variables. We chose the following quantity.

$$
X^{p}=\int \sigma_{i j} d\left|\varepsilon_{i j}^{p}\right|
$$

In order to describe the evolution of the critical state, the following expression is proposed:

$$
1-\frac{e_{r e f}^{\prime}}{e_{r e f}}=\frac{A X^{p}}{B+X^{p}}
$$

In Eqation 21, two material parameters $A$ and $B$ are used to control the evolution of the critical state.

Parameter A controls the limit of the evolution of the critical state. Biarez and Hicher (1994) have proposed correlations between $\mathrm{e}_{\max }, \mathrm{e}_{\min }$ and $\mathrm{C}_{\mathrm{u}}=d_{60} / d_{10}$. For values of $\mathrm{C}_{\mathrm{u}}$ higher than 10, $\mathrm{e}_{\max }$ and $\mathrm{e}_{\min }$ remain almost constant. At the same time, the authors have suggested that the critical state line could be defined by two points $\left(\mathrm{e}_{\max }, 0.1 \mathrm{MPa}\right)$ and $\left(\mathrm{e}_{\mathrm{min}}, 5 \mathrm{MPa}\right)$. Therefore, when $\mathrm{C}_{\mathrm{u}}$ reaches 10 , the critical line will not evolve anymore. The parameter $A$ can be defined from Figure 1. When $X^{p} \rightarrow \infty$, the following equations can be obtained. 


$$
1-\frac{e_{r e f}^{\prime}}{e_{r e f}}=A \quad \text { and } \quad e_{r e f}^{\prime}=e_{r e f}(C u=10)
$$

Parameter B accounts for the amount of grain ruptures, depending on the initial properties of the grains (mineralogy, shape, size, distribution). Poorly graded materials are more susceptible of grain ruptures than well graded ones (Kim 1995).Parameter $B$ is used to control the speed of evolution of the critical state during loading. The smaller $B$ is, the more easily the grain can be crushed and the critical state line will go down more rapidly.

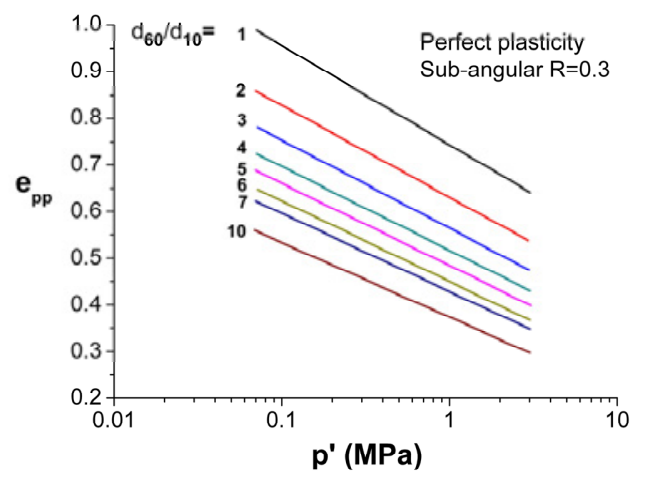

FIG. 1. Evolution of the critical state line with grain size distribution (after Biarez et Hicher, 1997).

\section{MODEL CALIBRATION}

In order to analyze the model's ability to reproduce the behaviors of granular materials when grain breakage occurs, we have simulated triaxial tests (Kim 1995) on crushed granite materials. The particle sizes vary from $6 \mathrm{~mm}$ to $12 \mathrm{~mm}$. The values of the constitutive parameters are given in Table 1. The results of the simulation are shown in Figure 2.

Table 1. Values of the parameters of the mode

\begin{tabular}{|c|c|c|c|c|c|c|c|c|c|c|c|}
\hline $\begin{array}{c}E \\
(\mathrm{MPa})\end{array}$ & $v$ & $e$ & $M c$ & $r_{e l}$ & $a$ & $e_{\text {ref }}$ & $\begin{array}{c}P_{r e f} \\
(\mathrm{kPa})\end{array}$ & $\lambda$ & $m$ & $A$ & $B$ \\
\hline 325 & 0.2 & 0.80 & 1.76 & 0.001 & 0.003 & 1.24 & 100 & 0.206 & 0.05 & 0.31 & 500 \\
\hline
\end{tabular}



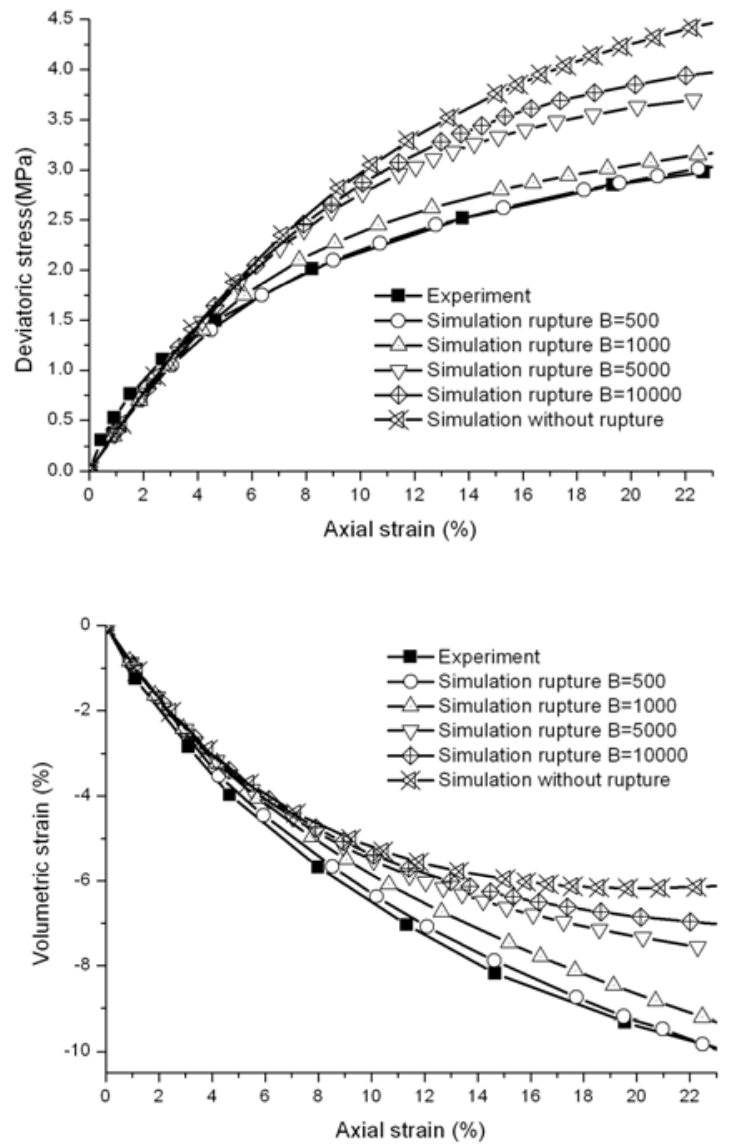

\section{FIG.2. Numerical simulation and experimental results of the granite under a cell pressure of $1 \mathrm{MPa}$ with different $\mathrm{B}$ values.}

Ruptures of particles can reduce the dilatancy of granular assemblies and increase the contractancy. Particle ruptures make specimens more likely to be compressed. The crushed granite material used here presents an important grading evolution. Particle breakage occurs rapidly, even at moderate confining stresses. The particle ruptures reduce the maximum strength of the specimen. The ruptures influence also the volume change: contractancy increases with the amount of grain ruptures. In the model, the rupture quantities of particles is controlled by parameter $\mathrm{A}$ and $\mathrm{B}$. The simulation results change corresponding to different values of $\mathrm{B}$. The ruptures increase as the parameter $\mathrm{B}$ decreases. When parameter B arrives at 500, the numerical results agree with the test results. 


\section{CONCLUSIONS}

Due to grains ruptures during loading, the physical features of the materials, such as the grading, change. As a consequence, the critical state changes also and its evolution modifies the material behaviour by reducing its maximum strength, decreasing the tendency to dilate or increasing the tendency to contract. The constitutive model can take into account the evolution of the critical state line during the loading process as a function of the dissipation of the energy. A first validation of the model was performed using tests results on crushed granite. We demonstrated the ability of the model to take into account the effects of grain ruptures on the stress-strain relationship and on the volume change.

\section{REFERENCES}

Bardet, J.P. (1990). "Lode dependences for isotropic pressure-sensitive elastoplastic materials", Journal of Applied Mechanics, Vol 57:1131-1146.

Biarez, J. and Hicher, P-Y. (1994). "Elementary Mechanics of Soil Behaviour", Balkema.

Biarez, J. and Hicher, P-Y. (1997). "Influence de la granulométrie et de son évolution par ruptures de grains sur le comportement mécanique de matériaux granulaires", Revue Française de Génie Civil, Vol. 1 (4) :607-631.

Dano, C. (2001). "Comportement mécanique des sols injectes". PHD thesis, Ecole Centrale de Nantes,France.

Daouadji, A., Hicher, P-Y. and Rahma, A. (2000). "An elastoplastic model for granular materials taking into account grain breakage", European Journal of Mechanics A/Solids, Vol. 20 (1):113-137.

Hardin, B.O. (1985). "Crushing of soil particles", Journal of Geotechnical Engineering, ASCE, Vol. 111 (10): :1177-1192.

Kim, M.S. (1995). "Etude Expérimentale du Comportement Mécanique des Matériaux Granulaires sous Fortes Contraintes ", PHD thesis, Ecole Centrale de Paris

Marsal, R.J. (1967). "Large scale testing of rockfill materials", Journal of the Soil Mechanics and Foundation Division, ASCE, Vol. 93 (SM2): 27-43.

Vesic, A.S. and Clough, G.W. (1968). "Behaviours of granular materials under high stresses", Journal of the Soil Mechanics and Foundations Division, ASCE, Vol. 94, (SM3): 661-668. 